\title{
Interleukin-13 is Expressed in Mouse Kidney Allograft Rejection and Mediates Proliferation of Renal Tubular Epithelium In Vitro
}

\author{
Raphael Thuillier*, Orlena Cheng and Roslyn B. Mannon
}

Transplantation Branch, National Institute of Diabetes, Digestive and Kidney Disease, National Institutes of Health, Bethesda MD 20892, USA

\begin{abstract}
Kidney transplantation is the preferred therapy for kidney failure. The leading cause of graft loss is chronic allograft nephropathy (CAN). We hypothesize that Interleukin-13 (IL-13), protective against acute kidney graft rejection, is involved in CAN. In mouse kidney allografts, we observe after 2 weeks signs of interstitial inflammation progressing to vasculitis. By 6 weeks, CAN is manifest. IL-13 is overexpressed in allografts versus isografts $(\mathrm{p}<0.01)$ throughout the post-transplant course. Concomitantly, we detect markers of fibrogenesis and epithelial-mesenchymal transition. To explore this phenomenon, kidney proximal tubular epithelial cells were cultured with IL-13. Within 6 hours, we show increased proliferation compared to untreated cells $(\mathrm{p}<0.01)$, occurring through activation of IL4R $\alpha / \mathrm{JAK} 3$ and Stat6 and blocked by anti-IL-13 monoclonal antibody. This is the first report of IL-13 inducing a specific biological activity in kidney epithelial cells with a possible role in the damage control machinery, indicating its potential as a biomarker and therapeutic target.
\end{abstract}

Keywords: Kidney transplant, chronic, injury, epithelial cell, IL-13.

\section{INTRODUCTION}

Kidney transplantation is the preferred mode of renal replacement therapy, due to advances in immunosuppressive medications that facilitate excellent short term graft survival with low levels of acute rejection. However, long term graft survival in kidney transplantation has not improved substantially [1]. The leading cause of late graft loss is an entity called chronic allograft nephropathy (CAN), characterized histologically by tubular atrophy (TA) and interstitial fibrosis (IF) [2] and may be accompanied by arteriosclerosis and glomerulosclerosis. CAN is characterized by a progressive decline in kidney graft function months to years after transplant, associated with hypertension and proteinuria. Both antigen dependent and independent factors may lead to its development, and the absence of specific treatments for this disorder leads to an eventual need for retransplantation. Identifying new targets to ameliorate this process is of utmost interest in the transplant community.

IL-13 is a pleoitropic cytokine, first discovered to inhibit inflammatory cytokine production [3]. IL-13 is produced by a wide variety of cells including T cells [3-6], natural Killer T cells [7], mast cells, basophils, and eosinophils [8]. While its ability to activate $\mathrm{B}$ lymphocytes and stimulate production of $\operatorname{IgE}$ and $\operatorname{IgG} 4$ is well described $[5,9]$, recent studies have linked IL-13 to fibrosis in a signal transducer and activator of transcription (Stat) 6-dependent fashion [10]. In both macrophages [11] and dendritic cells [12], IL-13 induces the 'alternative activation' pathway, which leads to the production of arginase type 1 (Arg-1), an enzyme which

*Address correspondence to this author at the Transplantation Branch, National Institute of Diabetes, Digestive and Kidney Disease, National Institutes of Health, Bethesda MD 20892, USA; Tel: 301-451-3351; Fax: 301451-6989; E-mail: thuillierr@niddk.nih.gov catalyzes the conversion of L-arginine into proline, and ultimately collagen. IL-13 also induces the production of transforming growth factor beta (TGF $\beta$ ) in macrophages, indirectly promoting fibrosis [13]. On the other hand, IL-13 was recently described to have a protecting role against acute rejection, as graft receiving IL-13 gene therapy showed a lower rate of injury [14].

Thus, while IL-13 is linked to fibrosis both directly and indirectly, it may also be protective in injury processes. We hypothesize that IL-13 may play a role in chronic allograft injury of kidney allografts with direct effects on renal tubular epithelium. To explore this possibility, we utilized a well characterized mouse model of kidney transplantation that develops acute rejection followed by severe chronic injury. Following kidney transplantation, rejecting allografts have markedly elevated levels of gene expression for IL-13, compared to non-rejecting, syngeneic control grafts and associated with other markers of fibrogenesis, prior to the development of TA/IF. Further, we show that IL-13 mediates proliferation in kidney tubular epithelial cells in vitro. These results suggest that IL-13 may induce cell proliferation in the proximal tubules, hence favoring cell replacement and impeding allograft fibrosis and tubular atrophy in kidney allografts. These studies are the first to link IL-13 with late graft failure and present a potential new target to improve allograft survival.

\section{MATERIALS AND METHODOLOGY}

\section{Animals}

C57BL/6 and (Balb/c X DBA/2) $\mathrm{F}_{1}$ mice were acquired from Jackson Laboratory (Bar Harbor, ME) or NCI (Frederick, MD) at 6-8 weeks of age. Kidneys from C57BL/6 (isografts) or MHC incompatible (Balb/c X DBA/2) $\mathrm{F}_{1}$ (allografts) were transplanted into C57BL/6. Mice were kept in 
the specific pathogen-free facility of the National Institute of Health and received standard laboratory chow and tap water ad libitum under approved institutional protocols in accordance with the NIH Guide for the Care and Use of Laboratory Animals.

\section{Mouse Kidney Transplantation}

Vascularized kidney transplants were performed as previously described [15]. Briefly, mice were anesthetized with isoflurane, and the donor kidney, ureter, and half of the bladder were harvested en bloc, including the renal artery with a small aortic cuff and the renal vein with a small caval cuff. These vascular cuffs were anastomosed to the recipient abdominal aorta and vena cava, respectively, below the level of the native renal vessels. Total cold ischemic time averaged 30-35 minutes. Donor and recipient bladders were attached dome to dome. The right native kidney was removed at the time of transplantation and the left native kidney was removed 7 days later. Overall surgical mortality was approximately $15 \%$, and there were no significant differences in perioperative mortality between the experimental groups. Mice were sacrificed at 2, 4, and 6 weeks post transplantation for further studies. Six animals were studied in each group. No immunosuppression was given as the grafts have prolonged survival with about $20 \%$ survival of all allografted animals at 6 weeks.

\section{Cell Culture}

Mouse proximal tubule epithelial cell line (MCT, a gift of Dr. Eric Neilson) and mouse macrophage cell line RAW264.7 (ATCC, Manassas, VA) were cultured in Dulbecco's Modified Eagle Medium with $4 \mathrm{mM}$ glutamine and 4.5 g glucose per liter, $\mathrm{pH} 7.1$ to 7.2, (DMEM, Invitrogen) with or without $10 \%$ Fetal bovine serum (FBS, Invitrogen).

\section{Quantitative Real Time PCR Analysis In Vivo}

A portion of the kidney was snap-frozen in liquid nitrogen and processed for RNA extraction using Trizol (Invitrogen, Carlsbad, CA). In Vitro: Cell culture experiments were stopped at 6,24 , or 48 hours. The media was removed and cells lysed using Trizol and processed for RNA extraction. For all samples, genomic DNA was removed using DNAfree kit (Ambion, Austin, TX). Each cDNA template for RTPCR was prepared by first-strand reverse transcription using random primers (First-strand cDNA synthesis kit; Roche, Indianapolis, IN). TaqMan PCR assays was performed in du/triplicate with 10ng total cDNA templates in 96-well optical plates on an ABI Prism 7700 Sequence Detection System following the manufacturer's recommendations (PE Applied Biosystems, Foster City, CA). Murine TaqMan gene expression assays were purchased from PE Applied Biosystems. For each sample, an amplification plot was generated, displaying an increase in the reporter dye fluorescence $(\Delta \mathrm{Rn})$ with each PCR cycle. A threshold cycle $\left(\mathrm{C}_{t}\right)$ value was calculated, which was the PCR cycle number at which fluorescence reached threshold, based on baseline variability data in the first 15 cycles. Delta-Ct for each gene target was obtained by subtracting the $\mathrm{Ct}$ value of $18 \mathrm{~S}$ rRNA from that of the gene target. Finally, the level of mRNA expression relative to expression in isografts was obtained by the following equation:
Relative expression $=2^{-(\mathrm{dCt} \text { of target in treatment group-dCt of target in normal }}$ tissue)

\section{Polymerase Chain Reaction}

PCR was performed using the HotStarTaq kit (Qiagen, Valencia, CA), following the manufacturer's recommendations. Primers for IL-13Ralphal were designed from the full cDNA sequence (NM_133990) using Oligoperfect designer (Invitrogen) to obtain a $1105 \mathrm{bp}$ long product. Forward primer: T T G G T G C T G C T A C T G T G G A C, reverse primer: C A G G A T C A G G A A T T G G A G G A. PCR products were run on a $1.2 \%$ agarose gel and photographed using a Kodak image 1D station (Kodak, New Haven, CT).

\section{Cell Proliferation and Viability}

Cells were seeded $(50,000$ cells $/ \mathrm{mL})$ and cultured for 24 hours, then washed with medium without serum and kept $24 \mathrm{~h}$ in a serum depleted environment. Cell proliferation was measured by following BrdU incorporation using a colorimetric ELISA test (Roche). Cells were cultured with BrdU labeling reagent in the appropriate media, the reaction was stopped at different time and the plates processed following the manufacturer's protocol. Signaling studies used mouse rIL-13 (Biosource. Camarillo, CA) with or without Rat anti mouse IL-13 monoclonal antibody $(500 \mathrm{ng} / \mathrm{mL}$, Sigma, St Louis, IL), Rabbit polyclonal anti TGF $\beta$ antibody (175ng/mL, Cell Signaling Technology, Danvers, MA) as well as the inhibitors A-81-01 (1 $\mu \mathrm{M}$, Sigma), Leflunomide

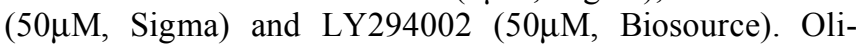
gonucleotide $(\mathrm{ODN})$ were also used in BrdU assays, for which cells were transfected with 300 pmol sense or antisense ODN specific to the Stat6 promoter, previously shown to significantly reduce Stat6 protein expression [16]. Transfection was performed using Lipofectamin 2000 (Invitrogen), following the manufacturer's recommendations Cell viability was measured using the Cell Proliferation Kit II (XTT) (Roche). Briefly, the cultured cells were exposed at different times to a yellow tetrazolium salt XTT solution. The salt molecules are cleaved by mitochondrial dehydrogenases into an orange formazan dye. This dye is quantified by a Victor3 plate reader (PerkinElmen, Boston, MA) at $490 \mathrm{~nm}$. This assay also reflects proliferation.

\section{TGFß1 Measurement}

Transforming growth factor concentration was measured using the multispecies TGF- $\beta 1$ immunoassay ELISA kit (Biosource). Medium from cells cultured with or without IL$13(0.1 \mathrm{ng} / \mathrm{mL})$ was isolated at different time points and processed following the manufacturer's recommendations. The resulting colorimetric reaction was quantified using a Victor3 (PerkinElmer) plate reader at $450 \mathrm{~nm} .3$ experiments were performed in duplicate, and the results are expressed as mean $\pm \mathrm{SEM}$.

\section{Western Blot Analysis}

Cells were lysed in RIPA lysis buffer (Santa Cruz Biotechnology, Santa Cruz, CA) per the manufacturer's guidelines. Samples were loaded Laemmli Sample buffer (BioRad, Hercules, CA) on a NuPage 4-12\% Bis-Tris gel (Invitrogen). Proteins were transferred onto PVDF membrane (GE Healthcare Bio-Sciences, Uppsala, Sweden). The mem- 
brane was incubated with Phospho-Stat6 and Stat6 antibody (Cell Signaling Technology, Danvers, MA) and fitting secondary antibodies. Detection was performed with Supersignal West Femto reagents (Pierce, Rockford, IL) and development with a Kodak image 1D station (Kodak). Quantitation of the protein bands was performed using the Kodak 1D imaging analysis software (Kodak). Normalization to protein loading was performed with G3PDH antibody (Chemicon international, Temecula, CA) on the same blot, after membrane-stripping.

\section{Statistical Analysis}

Data are shown as mean \pm SEM. Two-sided T -test was used for comparison between two groups, with significance defined as $\mathrm{p}<0.05$.

\section{RESULTS}

\section{Il-13 mRNA is Highly Expressed in Rejecting Kidney Allografts}

As we have previously described [17], fully-MHC mismatched kidney allografts develop acute rejection at 2 weeks (Fig. 1A) with marked interstitial inflammation consisting of lymphocytes and macrophages (data not shown). This inflammatory injury persists, and by 6 weeks, is accompanied
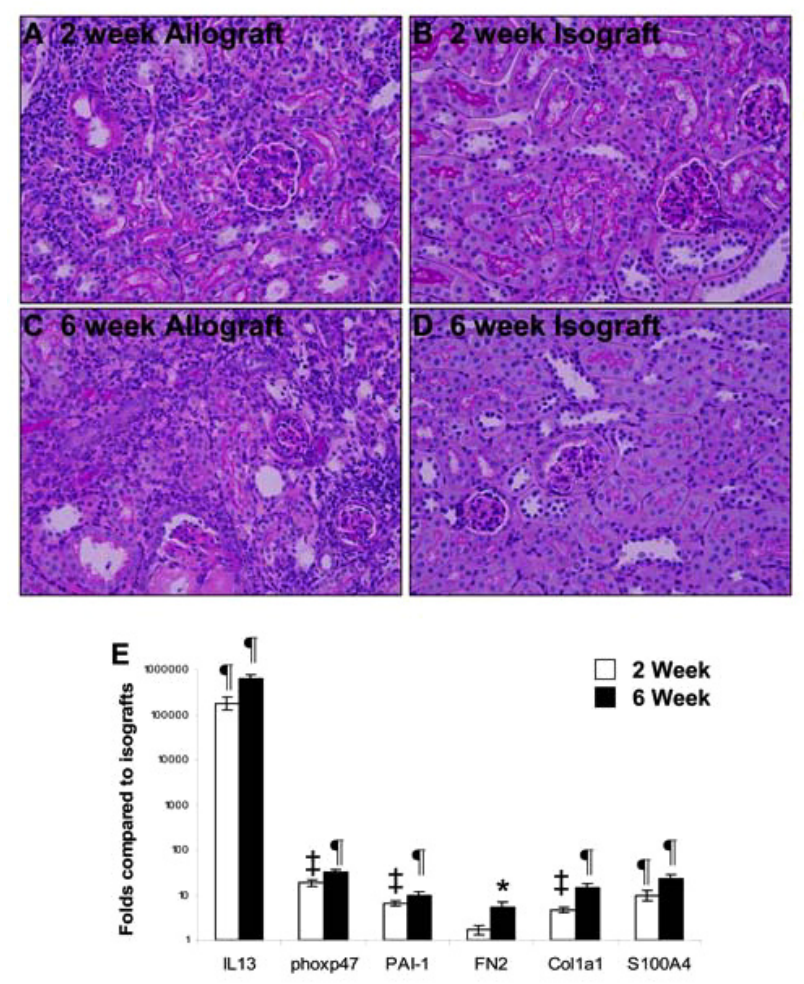

Fig. (1). Mouse kidney allografts develop acute rejection and subsequent tubular atrophy and interstitial fibrosis. Periodic Acid Schiff staining of 2 week old allograft (A) demonstrating marked inflammatory cell infiltration compared to the normal histology of an isograft (B). At 6 weeks, allografts demonstrate ongoing inflammation and tubular atrophy and interstitial fibrosis (C), compared to the relatively normal isografts (D). Magnification: 200x. Gene expression for IL-13 in allografts at 2 weeks (open bars) and 6 weeks (solid bars) determined by real time PCR. Results are expressed relative to isografted kidney as mean \pm SEM $(n=4)$. $* \mathrm{p}<0.05 ;$ I $\mathrm{p}<0.01 ; \neq \mathrm{p}<0.001$ compared to isografted kidneys. by tubular atrophy and interstitial fibrosis (Fig. 1C). In contrast, isografts retain relatively normal histology throughout the post transplant period (Fig. 1B and 1D). Accompanying these histological changes is a dramatic elevation in intragraft gene expression for IL-13 (Fig. 1E).

At 2 weeks, expression in allografts is markedly upregulated $\left(1.8 \times 10^{5} \pm 0.6 \times 10^{5}\right.$ fold $)$ compared to isografts $(\mathrm{p}<0.01)$, and remains elevated through 6 weeks $\left(6.2 \times 10^{5} \pm 1.5 \times 10^{5}\right.$ fold; $\mathrm{p}<0.01)$. Moreover, there is associated increased expression in allografts at both 2 and 6 weeks of Phoxp47 (18.4 \pm 3.4 fold and 31.2 \pm 6.0 -fold, respectively; $\mathrm{p}<0.01$ ), a marker of reactive oxygen species production, PAI-1 $(6.6 \pm 0.9$-fold and $9.2 \pm 2.1$-fold, respectively, $\mathrm{p}<0.01)$, fibronectin $(5.3 \pm 1.4$ fold; $\mathrm{p}<0.05$ at 6 weeks) and collagen $\mathrm{I} \alpha 1(4.8 \pm 0.6$-fold and 14.4 \pm 3.1 -fold; $\mathrm{p}<0.01$ ), markers of fibrosis and S100A4 $(9.8 \pm 2.5$-fold and $23.7 \pm 5.0$-fold; $\mathrm{p}<0.01)$, a marker of epithelial-mesenchymal transition, confirming previous findings [17]. Thus, IL-13 gene expression is induced in rejecting kidney allografts concomitantly with markers indicating a pro-fibrotic milieu.

\section{IL-13R $\alpha 1$ is Highly Expressed in Renal Tubular Cells}

To begin to understand the potential role of IL-13 in kidney allografts, we investigated the actions of IL-13 on tubular epithelial cells, one of the primary targets of immunemediated injury [18]. To determine if tubular epithelial cells had any response to IL-13, we first evaluated for expression of IL-13R $\alpha 1$, the isoform of the IL-13 receptor that is the known initiator of IL-13 signaling [10], in proximal tubule epithelial cells (PTECs) using the MCT cell line. RAW264.7, a macrophage cell line, was used as a positive control. As shown by agarose gel electrophoresis following PCR, PTECs cells express mRNA for the $\alpha 1$ isoform (Fig. $\mathbf{2 A}$ ). To determine the extent of expression, we also performed Taqman RT-PCR, calculating IL13R $\alpha 1$ expression in RAW cells relative to the expression level in PTECs. As shown in Fig. (2A), the level of IL-13R $\alpha 1$ in PTECs is similar to the levels in RAW cells. Thus, renal tubular epithelial cells express the IL-13R $\alpha 1$ and have the capacity to respond to IL-13.

\section{IL-13 Treatment Promotes PTEC Mitochondrial Activity and Proliferation}

Following transplantation, epithelial cells are affected not only by ischemic injury but immune mediated injury by lymphocytes. The impact of IL-13 on this process is not known. We thus investigated the effect of IL-13 in cultured PTECs. Small doses of IL-13 $(0.01 \mathrm{fg} / \mathrm{mL}$ to $0.1 \mathrm{pg} / \mathrm{mL})$ were added to serum deprived PTEC cells. At the lowest dose of $0.1 \mathrm{fg} / \mathrm{mL}$ of IL-13, after only $6 \mathrm{~h}$ of stimulation, XTT cleavage increased by $110.8 \pm 1.8 \%$ of control, $(\mathrm{p}<0.001$; Fig. 2 B $)$, indicating enhanced viability and/or proliferation. To confirm that the XTT cleavage indicates increased cell proliferation, we performed a BrdU incorporation assay over a wide range of dilutions (Fig. 2C). At 6 hours of IL-13 treatment, PTEC proliferation rate increased by $10 \%$ at $0.1 \mathrm{fg} / \mathrm{mL}$, peaking at $113.5 \pm 4.37 \%$ of control $(\mathrm{p}<0.05)$ at $1 \mathrm{pg} / \mathrm{mL}$.

To determine the specificity of this response to IL-13, we measured proliferation by IL-13 with and without monoclonal antibody directed against mouse IL-13 (Fig. 2D). While PTEC basal proliferation was unaffected by IL-13 

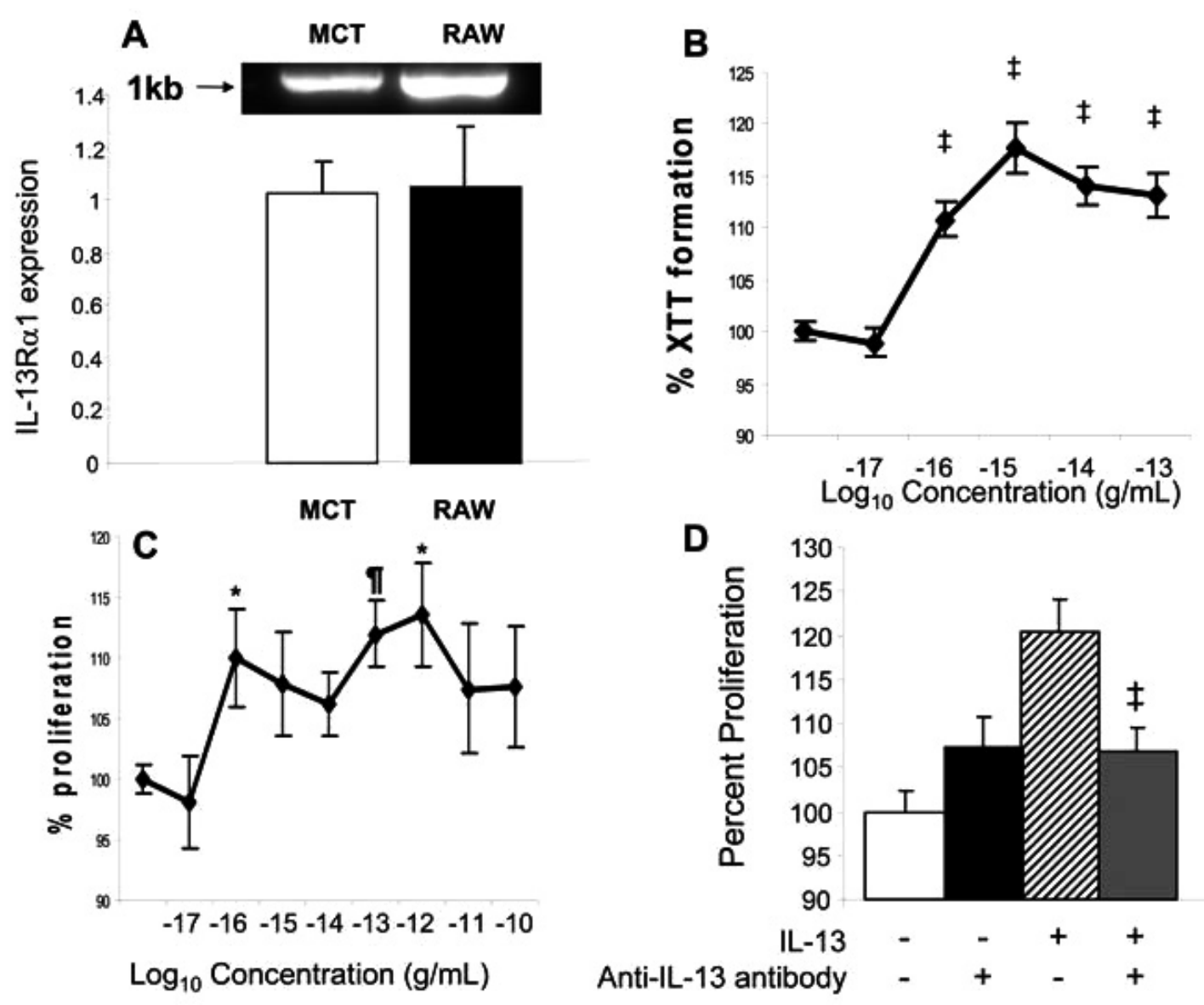

Fig. (2). Expression of IL-13R $\alpha 1$ and response of tubular epithelial cells to IL-13 treatment. Gene expression for the receptor is shown by agarose gel electrophoresis (A, top) and by real-time PCR (A, bottom panel) in both resting PTEC proximal tubular epithelial cells and RAW macrophages. Results are expressed as folds over PTEC as mean \pm SEM $(n=3)$. B. XTT viability assays on PTEC cells cultured in DMEM + $10 \%$ FBS for 6 hours with a gradient of IL-13 $(0.01 \mathrm{fg} / \mathrm{mL}$ to $0.1 \mathrm{pg} / \mathrm{mL})$. Assays were conducted as described in material and methods and are results expressed as mean \pm SEM for 6 separate experiments. There is an increase in cell viability with IL-13 stimulation, starting at $0.1 \mathrm{fg} / \mathrm{mL}$. C. Cell proliferation assay measured by BrdU incorporation on PTEC cells stimulated with increasing concentrations of rIL13, according to methods. Results are expressed as mean \pm SEM for 6 separate experiments. IL-13 increases cell proliferation by approximately $10 \%$ with exposure to $0.1 \mathrm{fg} / \mathrm{mL}$ of rIL-13 to a maximum of $13 \%$ with $1 \mathrm{pg} / \mathrm{mL}$. D. BrdU incorporation assay on PTEC cells comparing resting cells (open bar) with cells stimulated for 6 hours with $0.1 \mathrm{pg} / \mathrm{mL}$ rIL13 (IL13) with or without 50pg/mL rat anti mouse IL-13 antibody (IL13 mAb). A total of 6 experiments were performed and the results are expressed as the mean \pm SEM. Following exposure with rIL-13, there was a $20 \%$ increase in proliferation compared to resting cells. This effect was completely abrogated by incubation with anti-IL-13 antibody. ${ }^{*} \mathrm{p}<0.05$; II $\mathrm{p}<0.01 ; \neq \mathrm{p}<0.001$.

specific monoclonal antibody (107.2 $\pm 3.6 \%$ of control), the induction of proliferation with IL-13 (120.5 $\pm 3.5 \%$ of control) was almost completely blocked by co-incubation with anti-IL-13 antibody (106.8 $\pm 2.8 \%$ of control).

\section{IL-13 Induced-Proliferation is Independent of TGF $\beta$ Production}

As IL-13 is known to induce transforming growth factor beta (TGF $\beta$ ) production [13], we next measured the production of TGFB in the culture supernatant of PTECs. At 2 hours, $262.8 \pm 38.9 \mathrm{ng} / \mathrm{mL}$ of active TGF $\beta$ was measured in the supernatant. At 48 hours, PTECs continued to produce substantial levels of TGF $\beta(556.0 \pm 15.7 \mathrm{ng} / \mathrm{mL} ; \mathrm{p}<0.01 \mathrm{com}-$ pared to 2 hours). Exposure to IL-13 treatment $(0.1 \mathrm{ng} / \mathrm{mL})$ for 48 hours resulted in $544.0 \pm 9.0 \mathrm{ng} / \mathrm{mL}$ TGF $\beta$ measured, not different from untreated cells. To further explore the dependence of proliferation on TGF $\beta$ expression, cells were cocultured in the presence of A-81-01, a specific inhibitor of ALK5, a component of the TGF $\beta$ receptor complex. Based on BrdU incorporation, incubation with A-81-01 did not mitigate IL-13 driven proliferation $(125.3 \pm 6.1 \%$ of control) compared to the level of proliferation mediated by IL-13 alone $(123.6 \pm 4.7 \%$ of control; $p=N S)$. Similarly, neutralization of TGF $\beta$ in the media through the use of a polyclonal antibody specific to TGF $\beta$ (all isoforms), as described in the methods, had no effect IL-13 mediated proliferation (124.4 $\pm 5.1 \%$ of control) compared to treatment with IL-13 alone $(125.3 \pm 6.1 \%$ of control). Thus, in renal tubular epithelial cells, IL-13 induced proliferation appears independent of TGFß production. 


\section{IL-13 Signaling Through its Receptor}

The signaling pathway for IL-13 is complex and includes the primary receptor, IL-13R $\alpha 1$, which once bound induces recruitment of IL-4 receptor alpha 1 (IL4R $\alpha 1$ ), forming a high affinity heterodimer called IL-13R [19-21]. Heterodimerization induces the activation of Janus kinases linked to each chains (TYK2, JAK1 and JAK3), activation and translocation of Stat 6 [7, 22]. Additionally, IL4R $\alpha 1$ on activation may activate the p180 unit of phosphoinositol-3 kinase (PI3kinase) [23].

To assess whether a unique signaling pathway exists in renal tubular epithelium, we analyzed inhibitors of signaling pathways for known IL-13R signaling pathways. To determine if heterodimer signaling was present, we exposed cells to leflunomide, a known inhibitor of IL4R $\alpha$ and JAK3 [24]. As shown in Fig. (3A), treatment with $50 \mu \mathrm{M}$ leflunomide reduced IL-13 induced PTEC proliferation by $40 \pm 5.5 \%$ ( $\mathrm{p}<0.001)$ compared to IL-13 alone. Blockade of PI3-kinase using $50 \mu \mathrm{M}$ of the specific inhibitor LY294002 (Fig. 3A) resulted in a reduction of $20 \pm 7.9 \%$ in proliferation $(\mathrm{p}<0.05)$ in IL-13 stimulated PTEC cells. Thus, IL-13 induced proliferation is dependent on heterodimer IL-13R $\alpha 1 / \mathrm{IL}-4 \mathrm{R} \alpha$ complex, with activation of P3-kinase.

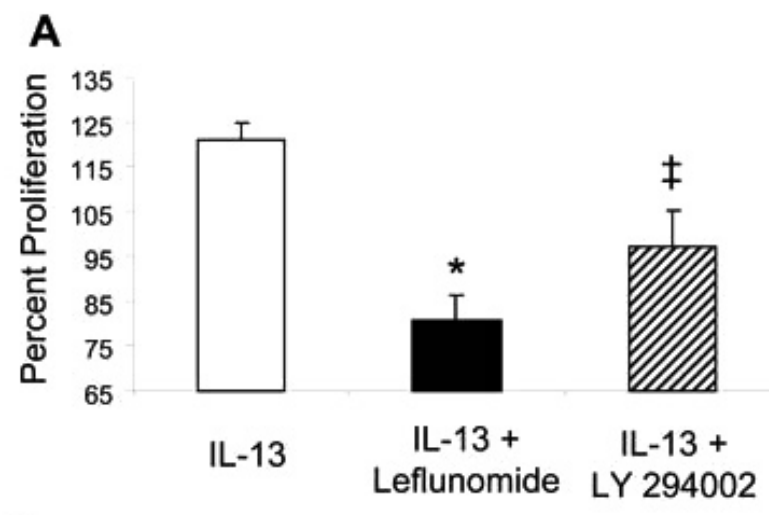

B
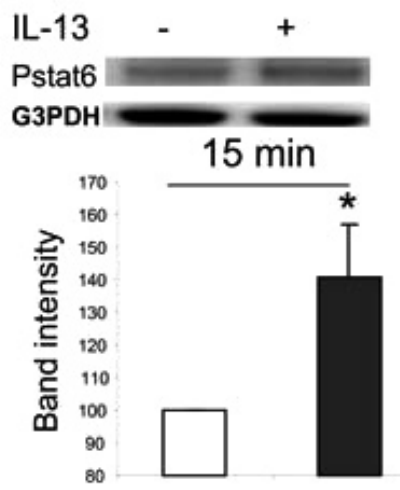

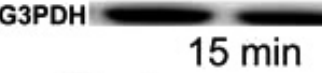

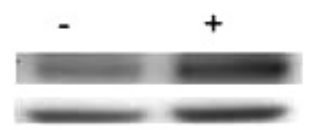

$60 \mathrm{~min}$
Fig. (3). IL-13 signals through standard IL-13R signaling pathways in renal tubular epithelial cells. In A, cell proliferation measured by BrdU incorporation assay on PTEC cells stimulated for 6 hours with $0.1 \mathrm{pg} / \mathrm{mL}$ rIL13 (IL13) in the absence or presence of leflunomide or PI3-kinase inhibitor LY294002. Results shown are mean +/- SEM of 12 experiments. There was a marked suppression of IL-13 induced proliferation with both of these agents. B. Representative blot with Phospho-Stat6 (Pst6) staining (B, top lanes) and Glyceraldehyde 3 Phosphate Dehydrogenase (G3PDH) as a control (B, bottom lanes). Signal quantification by Kodak Image 1D station of 3 independent experiments is shown below. IL-13 induces Stat6 phosphorylation 15 and 60 minutes following exposure on PTEC cells. In C, depletion of Stat6 protein level in PTECs by transfection of an antisens nucleotide is demonstrated by western blot. BrdU incorporation of PTEC transfected with a sense ODN or an antisense ODN against the Stat6 promoter, with or without 20ng/mL IL-13 (panel D). Antisense transfection abrogated IL-13-induced proliferation while sense had no effect. ${ }^{*} \mathrm{p}<0.05 ;$ II $\mathrm{p}<0.01 ; \neq \mathrm{p}<0.001$.
To test the activation and translocation of Stat-6, phosphorylated Stat- 6 was measured by western blot. When exposed to $0.1 \mathrm{pg} / \mathrm{mL}$ IL-13, Stat-6 phosphorylation increased by $140.7 \pm 16.4 \%$ of control $(p<0.05)$ at $15 \mathrm{~min}$ and by $2.6 \pm 8.7 \%$ of control at 60 minutes $(p<0.01)$. The funcoligonucleotide (ODN) strategy [16]. First, antissense ODN reduced the Stat6 protein levels to $69.9 \pm 5.6 \%$ of control, $\mathrm{p}<0.001$ of control over three independent experiments (Fig. 3C). Moreover, while sense ODN did not affect the level of IL-13 stimulated PTEC proliferation (Fig. 3D), incubation with antisense oligonucleotide inhibited IL-13-induced proliferation by $15.8+/-0.5 \% \quad(\mathrm{p}<0.001)$. Thus IL-13 induces Stat6 phosphorylation, a protein without which IL-13 induced proliferation is not possible. These results show that IL-13 exercise its proliferative effect on PTECs through its described signaling pathway: IL4R $\alpha / J A K 3$, PI3-kinase and Stat6.

\section{IL-13 does not Mediate Epithelial-Mesenchymal Transi- tion (EMT) of PTECs}

To address whether IL-13 may directly initiate a profibrotic response via the PTEC expressed receptor, we evaluated gene expression for a number of molecules associated
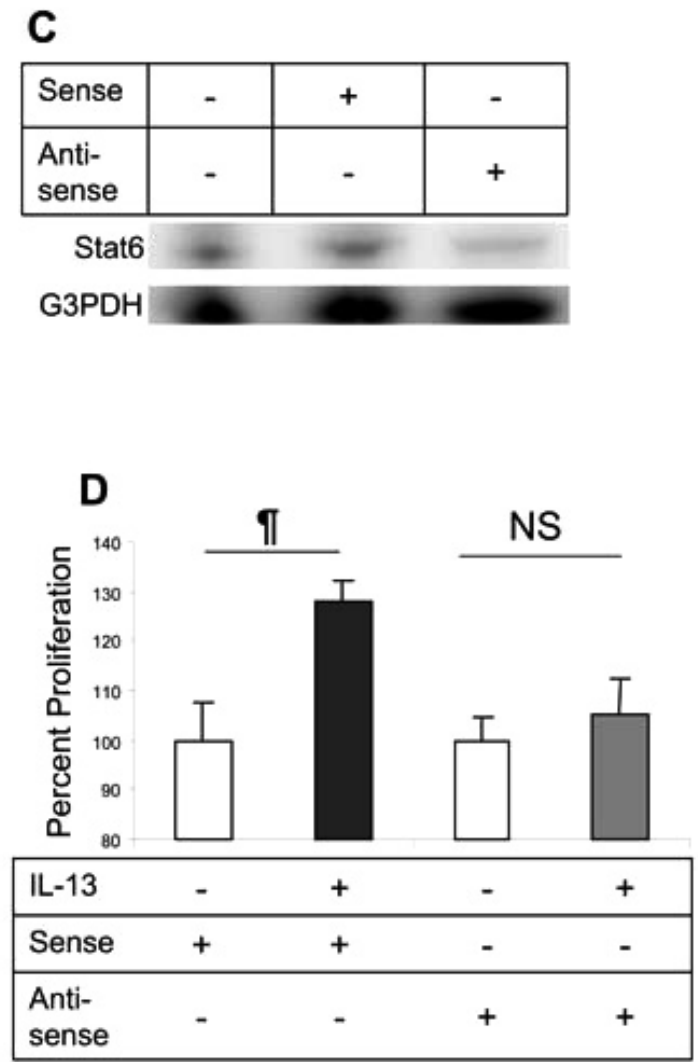
Table 1. Gene Expression Analysis in PTECs Following 20ng/mL IL-13 Exposure

\begin{tabular}{|c|c|c|c|c|c|c|c|c|c|}
\hline \multirow{2}{*}{ Genes } & \multicolumn{3}{|c|}{ 6 hours culture } & \multicolumn{3}{c|}{ 24 hours culture } & \multicolumn{3}{c|}{ 48 hours culture } \\
\cline { 2 - 10 } & Control & IL-13 & P & Control & IL-13 & P & Control & IL-13 & P \\
\hline \hline TGF3 & $1.2 \pm 0.3$ & $1.2 \pm 0.6$ & 0.89 & $1.3 \pm 1.1$ & $0.5 \pm 0.3$ & 0.10 & $1.2 \pm 0.7$ & $1.2 \pm 0.4$ & 0.99 \\
\hline CTGF & $1.2 \pm 0.4$ & $1.7 \pm 0.7$ & 0.42 & $1.1 \pm 0.4$ & $1.5 \pm 0.7$ & 0.16 & $1.1 \pm 0.6$ & $1.5 \pm 0.3$ & 0.21 \\
\hline S100A4 & $1.2 \pm 0.4$ & $1.0 \pm 0.2$ & 0.60 & $1.0 \pm 0.4$ & $2.8 \pm 1.5$ & 0.02 & $1.1 \pm 0.4$ & $1.3 \pm 0.4$ & 0.41 \\
\hline IGF1 & $1.1 \pm 0.3$ & $1.6 \pm 0.3$ & 0.10 & $\mathrm{n} / \mathrm{d}$ & $\mathrm{n} / \mathrm{d}$ & $\mathrm{n} / \mathrm{d}$ & $\mathrm{n} / \mathrm{d}$ & $\mathrm{n} / \mathrm{d}$ \\
\hline$\alpha$ SMA & $1.1 \pm 0.3$ & $1.8 \pm 0.5$ & 0.07 & $1.0 \pm 0.4$ & $0.9 \pm 0.8$ & 0.79 & $1.5 \pm 1.3$ & $2.5 \pm 3.3$ & 0.58 \\
\hline Vimentin & $1.2 \pm 0.4$ & $1.3 \pm 0.3$ & 0.70 & $1.1 \pm 0.7$ & $5.6 \pm 2.9$ & 0.004 & $1.0 \pm 0.2$ & $1.1 \pm 0.4$ & 0.69 \\
\hline Fibronectin & $1.2 \pm 0.4$ & $1.0 \pm 0.3$ & 0.62 & $1.0 \pm 0.2$ & $1.1 \pm 0.4$ & 0.69 & $1.0 \pm 0.3$ & $0.9 \pm 0.2$ & 0.38 \\
\hline E-cadherin & $1.1 \pm 0.2$ & $2.2 \pm 0.9$ & 0.11 & $1.1 \pm 0.5$ & $2.8 \pm 1.5$ & 0.02 & $1.1 \pm 0.5$ & $1.3 \pm 0.5$ & 0.51 \\
\hline MMP9 & $1.1 \pm 0.2$ & $0.7 \pm 0.1$ & 0.05 & $\mathrm{n} / \mathrm{d}$ & $\mathrm{n} / \mathrm{d}$ & $\mathrm{n} / \mathrm{d}$ & $\mathrm{n} / \mathrm{d}$ & $\mathrm{n} / \mathrm{d}$ & $\mathrm{n} / \mathrm{d}$ \\
\hline Bmp7 & $1.1 \pm 0.2$ & $1.5 \pm 0.5$ & 0.27 & $1.3 \pm 0.9$ & $1.1 \pm 0.8$ & 0.72 & $1.0 \pm 0.2$ & $0.8 \pm 0.1$ & 0.11 \\
\hline
\end{tabular}

Results are expressed as fold over expression in untreated control cells (mean \pm SEM) and a mean of 3 separate experiments. n/d: marker not detected.

with fibrosis and EMT in the kidney. As shown in Table 1, exposure of PTECs for 6 hours with $20 \mathrm{ng} / \mathrm{mL}$ of IL-13 did not induce any significant changes in expression of growth factors CTGF, IGF1 and TGF $\beta$, nor EMT markers S100A4, $\alpha S M A$, vimentin, E-cadherin, or fibronectin. Negative regulator BMP7 was also unaffected. However, there was a modest but significant decrease in expression in MMP-9 following IL-13 treatment. At 24 hours, expression of EMT markers S100A4 and vimentin were increased significantly, but accompanied also by an upregulation of E-cadherin. However, at 48 hours, these transcriptional differences between PTECs cultured alone or with $20 \mathrm{ng} / \mathrm{mL}$ IL-13 were not sustained. Thus, IL-13 does not directly mediate a durable profibrotic response in PTECs.

\section{DISCUSSION}

The etiology of chronic allograft injury and the development of tubular atrophy and interstitial fibrosis are not clear. At the center of this injury are tubular epithelial cells, which may undergo epithelial-mesenchymal transition (EMT), a critical event in fibrogenesis of kidney grafts [25, 26]. Through this process, tubular epithelial cells may lose their epithelial properties, and adopt a mesenchymal phenotype leading towards cell proliferation, migration out of the tubule, and formation of a pro-fibrotic machinery inside as well as outside of the tubule [26-33]. Real time PCR analysis of the gene expression profile in PTECs stimulated with IL13 at 24 hours demonstrates upregulation of two markers for EMT but with over-expression of E-cadherin, which is not supportive of EMT. Moreover, these changes are not sustained over time and thus we cannot draw a firm conclusion regarding the direct influence of IL-13 on EMT or fibrosis in these cells. IL-13 impact on proliferation could play a role in the proliferative phase of EMT, therefore accelerating the pace of mesenchymal cell production and potentially aggravating fibrosis. On the other hand, as cell proliferation is integral to recovery of tubular damage, IL-13 may limit the extent of the injury, promoting replacement of dead and apoptotic cells, and thus slowing graft deterioration. The later is in concordance with recent studies by Sandovici $e t$ al.[14], which indicate that IL-13 gene therapy of kidney graft could attenuate acute allograft rejection, a phenomenon for which IL-13 driven PTEC proliferation may support. Experiments such as depletion of IL-13 in vivo using antibodies [6] or chimeric protein [34] could provide clues towards determining the exact role played by this cytokine. Th2 cytokines have been typically associated with $\mathrm{T}$ cell proliferation, stimulation of B cells including immunoglobulin production and the allergic response [35]. While Th2 associated fibrosis has been noted, the mechanism of this response remains unclear and a direct effect of a $\mathrm{T}$ cell based cytokine on epithelial cells as we have demonstrated here is uncommon. Recent studies suggest that IL-13 induces fibrosis via a TGF $\beta$ dependent mechanism in association with TGF $\beta$ activation [13]. Our studies did not demonstrate an induction of TGF $\beta$ transcription, and this difference may be related to the fact that purified epithelial cells were used whereas prior observations were in vivo, with a macrophagerich milieu. We also tested the effect of IL-4, another Th-2 cytokine which shares a common receptor chain with IL-13, and found a similar potential for inducing proliferation, albeit at a slower pace ( 24 hours instead of 6 hours, data not shown). Thus Th2 cytokines present within the allograft may not only affect other inflammatory cells within the graft, but may potenciate damage recovery mechanisms by moderating epithelial responses to injury and could thus be contributory to extend the life of the graft. Investigating the influence of the use of immunosuppressive regimes on these processes could permit to better design therapies that are not so detrimental to the long term state of the graft and could potentially harness the power of the immune system towards delaying graft failure.

With the growing interest in non-invasive diagnostic tools such as mRNA analysis of the urine [36] or the blood [37], particularly with high-throughput techniques [38], there is increasing need for new markers of chronic injury. Particularly of interest for diagnostic purposes, these markers need to allow detection of the disease before the process be- 
comes irreversible. Herein we demonstrate that IL-13 is detected in the graft several weeks before the development of histological features of the injury, and furthermore we demonstrate in vitro the direct influence of this factor on PTECs, increasing their proliferation rate and possibly slowing down the injury process. Consequently, investigating the levels of expression of IL-13 in the blood or urine of patients could provide an early sign of developing chronic injury.

\section{CONCLUSIONS}

In kidney transplantation, the leading cause of this graft loss is chronic allograft nephropathy (CAN), histologically characterized by tubular atrophy (TA) and interstitial fibrosis (IF). We demonstrate that in fully-vascularized mouse model of kidney transplantation, allografts show a marked elevation in the gene expression of IL-13 along with markers of chronic injury. Furthermore, we show that in vitro, IL-13 induces proximal tubule cell proliferation, suggesting the possible involvement of IL-13 in a mechanisms at the core of damage control during tubular injury. This is the first report of a possible protective biological activity for IL-13 in kidney epithelial cells. Understanding the IL-13 pathway will provide a new diagnostic and therapeutic target for patients with CAN.

\section{CONFLICT OF INTEREST:}

The authors have had no involvements that might raise the question of bias in the work reported or in the conclusions, implications, or opinions stated.

\section{ACKNOWLEDGEMENTS}

This work as supported by the intramural research program, National Institute of Diabetes and Digestive and Kidney Diseases (1 Z01 DK062008-05 DIR).

\section{REFERENCES}

[1] Meier-Kriesche HU, Schold JD, Srinivas TR, Kaplan B. Lack of improvement in renal allograft survival despite a marked decrease in acute rejection rates over the most recent era. Am J Transplant 2004; 4(3): 378-83.

[2] Racusen LC, Solez K, Colvin RB, et al. The Banff 97 working classification of renal allograft pathology. Kidney Int 1999; 55(2): 713-23.

[3] McKenzie AN, Culpepper JA, de Waal MR, et al. Interleukin 13, a T-cell-derived cytokine that regulates human monocyte and B-cell function. Proc Natl Acad Sci USA 1993; 90(8): 3735-39.

[4] Minty A, Chalon P, Derocq JM, et al. Interleukin-13 is a new human lymphokine regulating inflammatory and immune responses. Nature 1993; 362(6417): 248-50.

[5] Punnonen J, Aversa G, Cocks BG, et al. Interleukin 13 induces interleukin 4-independent IgG4 and IgE synthesis and CD23 expression by human B cells. Proc Natl Acad Sci USA 1993; 90(8): 3730-34.

[6] Yang G, Li L, Volk A, et al. Therapeutic dosing with antiinterleukin-13 monoclonal antibody inhibits asthma progression in mice. J Pharmacol Exp Ther 2005; 313(1): 8-15.

[7] Izuhara K, Arima K. Signal transduction of IL-13 and its role in the pathogenesis of bronchial asthma. Drug News Perspect 2004; 17(2): 91-98.

[8] Gessner A, Mohrs K, Mohrs M. Mast cells, basophils, and eosinophils acquire constitutive IL-4 and IL-13 transcripts during lineage differentiation that are sufficient for rapid cytokine production. J Immunol 2005; 174(2): 1063-72.

[9] Mentink-Kane MM, Wynn TA. Opposing roles for IL-13 and IL-13 receptor alpha 2 in health and disease. Immunol Rev 2004; 202 : 191-202.

[10] Wynn TA. IL-13 effector functions. Annu Rev Immunol 2003; 21: 425-56.
[11] Modolell M, Corraliza IM, Link F, Soler G, Eichmann K. Reciprocal regulation of the nitric oxide synthase/arginase balance in mouse bone marrow-derived macrophages by TH1 and TH2 cytokines. Eur J Immunol 1995; 25(4): 1101-04.

[12] Munder M, Eichmann K, Moran JM, Centeno F, Soler G, Modolell M. Th1/Th2-regulated expression of arginase isoforms in murine macrophages and dendritic cells. J Immunol 1999; 163(7): 377177.

[13] Lee CG, Homer RJ, Zhu Z, et al. Interleukin-13 induces tissue fibrosis by selectively stimulating and activating transforming growth factor beta(1). J Exp Med 2001; 194(6): 809-21.

[14] Sandovici M, Deelman LE, van Goor H, Helfrich W, de Zeeuw D, Henning RH. Adenovirus-mediated interleukin-13 gene therapy attenuates acute kidney allograft injury. J Gene Med 2007; 9(12): 1024-32.

[15] Mannon RB, Nataraj C, Kotzin BL, et al. Rejection of kidney allografts by MHC class I-deficient mice. Transplantation 1995; 59(5): 746-55.

[16] Hill S, Herlaar E, Le Cardinal A, van Heeke G, Nicklin P. Homologous human and murine antisense oligonucleotides targeting stat6. Functional effects on germline cepsilon transcript. Am J Respir Cell Mol Biol 1999; 21(6): 728-37.

[17] Cheng O, Thuillier R, Sampson E, et al. Connective Tissue Growth Factor is a Biomarker and Mediator of Kidney Allograft Fibrosis. Am J Transplant 2006; 6(10): 2292-306.

[18] Kelley VR, Diaz-Gallo C, Jevnikar AM, Singer GG. Renal tubular epithelial and $\mathrm{T}$ cell interactions in autoimmune renal disease. Kidney Int Suppl 1993; 39: S108-15.

[19] Aman MJ, Tayebi N, Obiri NI, Puri RK, Modi WS, Leonard WJ. cDNA cloning and characterization of the human interleukin 13 receptor alpha chain. J Biol Chem 1996; 271(46): 29265-270.

[20] Andrews AL, Holloway JW, Puddicombe SM, Holgate ST, Davies DE. Kinetic analysis of the interleukin-13 receptor complex. J Biol Chem 2002; 277(48): 46073-78.

[21] Miloux B, Laurent P, Bonnin O, et al. Cloning of the human IL$13 \mathrm{R}$ alpha1 chain and reconstitution with the IL4R alpha of a functional IL-4/IL-13 receptor complex. FEBS Lett 1997; 401(2-3): 163-66.

[22] Kelly-Welch AE, Hanson EM, Boothby MR, Keegan AD. Interleukin-4 and interleukin-13 signaling connections maps. Science 2003; 300(5625): 1527-28.

[23] Nelms K, Huang H, Ryan J, Keegan A, Paul WE. Interleukin-4 receptor signalling mechanisms and their biological significance. Adv Exp Med Biol 1998; 452: 37-43.

[24] Siemasko K, Chong AS, Jack HM, Gong H, Williams JW, Finnegan A. Inhibition of JAK3 and STAT6 tyrosine phosphorylation by the immunosuppressive drug leflunomide leads to a block in IgG1 production. J Immunol 1998; 160(4): 1581-88.

[25] Djamali A, Reese S, Yracheta J, Oberley T, Hullett D, Becker B. Epithelial-to-mesenchymal transition and oxidative stress in chronic allograft nephropathy. Am J Transplant 2005; 5(3): 500-09.

[26] Vongwiwatana A, Tasanarong A, Rayner DC, Melk A, Halloran PF. Epithelial to mesenchymal transition during late deterioration of human kidney transplants: the role of tubular cells in fibrogenesis. Am J Transplant 2005; 5(6): 1367-74.

[27] Iwano M, Plieth D, Danoff TM, Xue C, Okada H, Neilson EG. Evidence that fibroblasts derive from epithelium during tissue fibrosis. J Clin Invest 2002; 110(3): 341-50.

[28] Kalluri R, Neilson EG. Epithelial-mesenchymal transition and its implications for fibrosis. J Clin Invest 2003; 112(12): 1776-84.

[29] Lan HY. Tubular epithelial-myofibroblast transdifferentiation mechanisms in proximal tubule cells. Curr Opin Nephrol Hypertens 2003; 12(1): 25-29.

[30] Liu Y. Epithelial to mesenchymal transition in renal fibrogenesis: pathologic significance, molecular mechanism, and therapeutic intervention. J Am Soc Nephrol 2004; 15(1): 1-12.

[31] Robertson H, Ali S, McDonnell BJ, Burt AD, Kirby JA. Chronic renal allograft dysfunction: the role of $\mathrm{T}$ cell-mediated tubular epithelial to mesenchymal cell transition. J Am Soc Nephrol 2004; 15(2): 390-97.

[32] Yang J, Liu Y. Dissection of key events in tubular epithelial to myofibroblast transition and its implications in renal interstitial fibrosis. Am J Pathol 2001; 159(4): 1465-75.

[33] Zeisberg M, Kalluri R. The role of epithelial-to-mesenchymal transition in renal fibrosis. J Mol Med 2004; 82(3): 175-81. 
[34] Chiaramonte MG, Schopf LR, Neben TY, Cheever AW, Donaldson DD, Wynn TA. IL-13 is a key regulatory cytokine for Th2 cellmediated pulmonary granuloma formation and IgE responses induced by Schistosoma mansoni eggs. J Immunol 1999; 162(2): 920-30.

[35] Zhou Y, McLane M, Levitt RC. Th2 cytokines and asthma. Interleukin-9 as a therapeutic target for asthma. Respir Res 2001; 2(2): 80-84.

[36] Yannaraki M, Rebibou JM, Ducloux D, et al. Urinary cytotoxic molecular markers for a noninvasive diagnosis in acute renal transplant rejection. Transpl Int 2006; 19(9): 759-68.
[37] Brouard S, Mansfield E, Braud C, Li L, Giral M, Hsieh SC et al. Identification of a peripheral blood transcriptional biomarker panel associated with operational renal allograft tolerance. Proc Natl Acad Sci USA 2007; 104(39): 15448-453.

[38] Halloran PF, Einecke G. Microarrays and transcriptome analysis in renal transplantation. Nat Clin Pract Nephrol 2006; 2(1): 2-3.

Received: March 24, 2008

Revised: May 01, 2008

Accepted: May 01, 2008

(c) Thuillier et al.; Licensee Bentham Open.

This is an open access article distributed under the terms of the Creative Commons Attribution License (http://creativecommons.org/licenses/by/2.5/), which permits unrestrictive use, distribution, and reproduction in any medium, provided the original work is properly cited. 